\title{
An Indian study: impact of COVID-19 on clinical decision-making and consensus in cardiac surgery practice across the country
}

\author{
Mohammed Idhrees $^{1}$ (D) $\cdot$ Chandrasekar Padmanabhan ${ }^{2} \cdot$ Kuppan Jagadeesan $^{3} \cdot$ Bashi Velayudhan $^{1}$
}

Received: 2 June 2020 / Revised: 12 July 2020 / Accepted: 22 July 2020 / Published online: 11 August 2020

(C) Indian Association of Cardiovascular-Thoracic Surgeons 2020

\begin{abstract}
Purpose There is a paucity of evidence and guidelines to support clinical decisions in the present unprecedented time. We aimed to use the experience and consensus of the cardiac surgeons for clinical decisions until evidence-based guidelines are formed. Methods An electronic questionnaire was emailed to all the 1434 members of the Indian Association of Cardiovascular and Thoracic Surgery, starting from May 13, 2020, and the members were followed up with reminder emails. For a wider reach, social media like WhatsApp was also used to circulate the questionnaire. Participation was voluntary and anonymized. An effective consensus was considered when $>70 \%$ opted the same opinion, and moderate consensus when $>50 \%$ opted the same opinion.

Results A total of 174 responses were obtained from the surgeons across the country. An effective consensus was obtained for the following: (i) emergency surgery in acute type A aortic dissection, (ii) urgent surgery in significant left main stem disease and mitral/aortic valves with pulmonary oedema, (iii) elective surgery in stable triple vessel disease and (iv) preoperative nasal swab examination for all patients undergoing surgery.

Conclusion In the present era, where evidence is evolving and the country is entering a phase after lockdown, the surgeons face a dilemma in operating patients. These consensuses provide interim recommendation; still further evidence is published.
\end{abstract}

Keywords COVID-19 · Coronavirus · Clinical decision · Personal protection equipment $\cdot$ RT PCR $\cdot$ CT chest

\section{Introduction}

A small spark from the Wuhan Province, China, has turned into a wildfire across the globe. The Great Wall of China is no more a fortress. The romance and the kisses in the Champ de Mars surrounding the Eiffel tower have dried up. Not visiting parents and friends has become an act of love. Tender, love and care were practised by social distancing. 'Video consultations' among doctors has become a common practice. Thanks to the few ribonucleic acid (RNA) strands-severe acute respiratory syndrome coronavirus 2 (SARS-CoV-2).

Mohammed Idhrees

a.m.idhrees@gmail.com

1 Institute for Cardiac and Aortic Disorders, SRM Institutes for Medical Science (SIMS Hospitals), Chennai 600 026, India

2 Division of Cardiothoracic Surgery, GKNM Hospital, Coimbatore, India

3 Central Health Services, MoHFW, Government of India, New Delhi, India
This pandemic has an unprecedented impact on clinical decision-making among physicians. There is a paucity of evidence and guidelines; experience and consensus continued to support the physician at the moment.

\section{Indian health care-diversity in its foundation}

India is a land of cultural diversity - so is medical practice. We have hospitals supported by the central government, state government, private bodies, multinational companies and industries/factories. The medical practice varies between the different establishments and different states and between urban and rural. The public sector provides $18 \%$ of the total outpatient care and $44 \%$ of inpatient care. The private health care accounts for $58 \%$ of the hospitals in the country and is clustered in urban India. Seventy-four percent of graduate doctors live in urban areas, serving $28 \%$ of the national population [1]. As on July 1, 2020, India stands fourth in position among the countries with maximum cumulative cases. The 
rise in the number of new cases has plateaued or decreased in countries like the USA, the UK and Italy, while in India, the curve still continues to rise $[2,3]$.

Among the surgical super specialties, cardiac surgery is one of the largest specialities to use intensive care unit (ICU) beds. In the present scenario, there is a reallocation of the ICU beds and the operating room (OR) to help coronavirus 2019 (COVID-19) patients. Elective cardiac surgeries have been postponed or stopped at many centres during the period of nationwide lockdown. The intent of postponing or cancelling cardiac operations are (i) protecting the cardiac patient from undue morbidity and mortality, (ii) protecting the institution and society at large and (iii) protecting the health care team [4]. The Government of India (GOI) has lifted the lockdown from June 1, 2020, with a few restrictions. As we resume surgeries after the lockdown, we would be encountering a different subset of patients-COVID-positive, COVIDsurvivor and COVID-negative patients. All of these will impact our clinical decision and practice. In these circumstances where evidence is lacking, the consensus among the cardiac surgery fraternity may provide an interim guideline for clinical decision-making. In view of this, we conducted an electronic survey with a series of questionnaires hoping that they qualitatively capture the experiences and views.

\section{Methods}

\section{Aim of the study}

The aims of the study are as follows: (i) to assess the impact of COVID-19 on clinical decision-making during the lockdown and (ii) to provide a practical consensus in regard to prioritization of cases, investigation and personal protective equipment (PPE) from the surgeons' across the country working in different health care systems with different years of experience.

\section{Study design and sampling}

This is an observational cross-sectional survey that included the cardiothoracic surgeons practising in India. An electronic survey was prepared with 26 questions using Google Form. These questions were emailed to all the 1434 registered Indian Association of Cardiovascular and Thoracic Surgery (IACTS) members starting from May 13, 2020. A second reminder email was sent on May 17, 2020. For a wider reach, social media like WhatsApp was used for the circulation of the questionnaire. In view of the current climate and the need for a timely outcome, we closed the survey on May 24, 2020, for further processes and analysis. Participation was voluntary and anonymized.

\section{Study population/responders}

Responders were cardiothoracic surgeons who are practising in India only.

\section{Inclusion and exclusion criteria}

All the survey which was completed was taken into consideration for analysis. The following respondents were not included in the study cohort: (i) Indian cardiothoracic surgeons practising abroad; (ii) residents who have not completed their training program.

\section{Primary endpoint}

The primary endpoint was the surgeons's decision on prioritizing cardiac surgery patients during the COVID-19 lockdown.

\section{Secondary endpoint}

The secondary endpoint were as follows: consensus of patient scheduling, preoperative screening and personal protection during the COVID-19 pandemic; the difference in clinical practice comparing the "COVID hot cities'/"COVID hot states' with the rest of the country.

\section{Statistical analysis}

Comparisons between these different groups were performed using Pearson's chi-square test or Fisher's exact test, as appropriate.

\section{Definition}

It was predetermined that an 'effective consensus' would be labelled when more than $70 \%$ of surgeons agreed on the same option. A 'moderate consensus' would be considered when more than $50 \%$ of surgeons agreed on the same option. As on May 29, 2020, at the time of analysis, four statesMaharashtra, Tamil Nadu, Gujarat, and Delhi-accounted for $66.74 \%$ of the country's total case volume and hence were categorized as 'COVID hot states'. The four cities-Delhi, Mumbai, Chennai, and Ahmedabad - had more than 10,000 cases each and accounted for $45.7 \%$ of the nation's COIVD 19 case volume and were categorized as 'COVID hot cities'. This was used to analyze and compare the clinical practice between the COVID hot cities/states with the rest of the country. 


\section{Ethical statement}

This is an electronic survey which involves the cardiovascular and thoracic surgeons of India. There is no human or animal experiment involved. The identity of the surgeons was anonymized in the survey. An expedited clearance was obtained from the Institutional Review Board.

\section{Results}

\section{Surgeons' demographic}

A total of 174 responses were based on achieving $70 \%$ consensus with $95 \%$ level of confidence and $7 \%$ absolute error (143 in the initial email and remaining 31 in the subsequent reminders). The questionnaire and the result of the survey are presented in Table 1. The total response of surgeons across different states and union territories is depicted in Fig. 1, while Fig. 2 shows the number of participants in different cities. Nearly two-thirds of respondents worked in the private sector $(n=113,64.9 \%)$. More than half of the public sector hospitals who participated were named as 'Dedicated COVID centres' by the GOI $(33 / 61$ vs. $26 / 113, P=0.004)$. Nearly three-fourths of the respondents $(n=128,73.56 \%)$ work in a centre where they operate more than 250 cases per year. Younger surgeons with less than 10-year experience contributed $51.7 \%(n=90)$ of the survey, while senior surgeons with $>25$ years' experience contributed $16.1 \%(n=$ 28) of the cohort.

\section{Impact of COVID on clinical practice}

A quarter of the surgeons $(n=47,27 \%)$ did not perform surgery after the lockdown from March 24, 2020. This was more common is COVID hot states (31/91 vs. $16 / 83, P=0.09)$. A majority of the participants $(n=118,87.42 \%)$ responded they have stopped elective surgery prior to March 31,2020. A few surgeons across all the states and zones $(n=30,22.2 \%)$ continued to perform elective surgery after the lockdown. Interestingly majority of these surgeons $(n=24 / 30)$ who continue to perform elective surgeries were from high-volume centres ( $>250$ cases/year). Among the surgeries which were performed during the lockdown, the most common operation was coronary artery bypass grafting (CABG) for triple vessel disease (TVD) with chest pain at rest and significant left main stem disease (LMSD) without chest pain. A few surgeons have performed acute type A aortic dissection (ATAAD) $(n=25)$ and emergency aortopulmonary shunt for congenital heart disease (CHD) $(n=28)$ during this period.

The bulk of surgeons who performed elective surgery during this era $(n=105,89 \%)$ agreed that there is a drop of more than $50 \%$ of surgical volume during this period. At the time of the survey, more than two-thirds of the surgeons $(n=111$, $68.52 \%$ ) have not restarted the elective surgery. Most of the surgeons planned to resume elective surgery, in the second half of May $(n=44,39.6 \%)$ or first half of June $(n=46$, $41.4 \%)$. A few surgeons consider reopening in July ( $n=17$, $15.3 \%$ ). The surgeons who work in public sectors opt to reopen in July as compared with the colleagues who work in private sectors $(13 / 61$ vs. $4 / 113, P=0.0008)$. This pattern of reopening in July was also resonated by surgeons who work in COVID hot cities $(13 / 72$ vs. $4 / 102, P=0.005)$ and COVID hot states $(14 / 91$ vs. $3 / 83, P=0.01)$.

A few surgeons agreed that their 'traditional' postsurgery ICU had been transformed into a dedicated COVID-unit ICU $(n=21,12.1 \%)$. This was significantly more common in the public sector $(13 / 61$ vs. $8 / 113$, $P=0.16)$, COVID hot cities $(15 / 72$ vs. $6 / 102, P=$ $0.008)$, and COVID hot states (17/91 vs. $4 / 83, P=$ 0.01). Among the surgeons who responded, none of them had operated on a COVID-positive patient or a patient who turned positive after cardiac surgery or performed an extracorporeal membrane oxygenation (ECMO) on a COVID-19 patient.

\section{Consensus on preoperative investigations and surgery (Figs. 3 and 4)}

Effective consensus The following were the effective consensus for prioritization of surgical patients: (a) acute aortic dissection has to be operated as an emergency procedure $(87.93 \%)$. (b) Significant LMSD without chest pain (69.54\%) and aortic/mitral valve patients with pulmonary oedema $(70.11 \%)$ are to be considered for urgent surgery. (c) Stable TVD (91.38\%) and aortic/mitral valve patients without pulmonary oedema $(92.53 \%)$ can be considered for elective surgery.

Moderate consensus The following were the moderate consensus for prioritization of surgical patients: (a) ascending aortic aneurysm $>5.5 \mathrm{~cm}$ in non-aortopathy (bicuspid aortic valve $[\mathrm{BAV}] /$ connective tissue disorder [CTD]) cohort to be considered as within 2 days $(51.15 \%)$; (b) ascending aortic aneurysm $>4.5 \mathrm{~cm}$ in aortopathy (BAV/CTD) cohort to be considered for the elective procedure $(60.34 \%)$; (c) TVD with chest pain at rest to be considered for surgery as urgent $(50 \%)$.

The following were the consensus in regard to preoperative investigation for surgical patients: (a) preoperative nasal swab examination in all patients undergoing cardiac surgery $(50.62 \%)$. (b) All the participants also agreed that they will do a nasal swab if the patients present had any contact history with a COVID patient $(51.92 \%)$. 
Table 1 The questionnaire and the response of the participants

\begin{tabular}{|c|c|c|}
\hline \multirow[t]{2}{*}{1} & \multicolumn{2}{|l|}{ State / Union Territory* (174 response) } \\
\hline & Figure 1 & \\
\hline \multirow[t]{2}{*}{2} & \multicolumn{2}{|l|}{ City* (174 response) } \\
\hline & Figure 2 & \\
\hline \multirow[t]{3}{*}{3} & \multicolumn{2}{|l|}{ The hospital I work belong to .................. Sector* (174 response) } \\
\hline & Public & $61(35.1 \%)$ \\
\hline & Private & $113(64.9 \%)$ \\
\hline \multirow[t]{3}{*}{4} & \multicolumn{2}{|c|}{$\begin{array}{l}\text { Is your centre a 'dedicated COVID-19 hospital' as per the Government of India? * (174 } \\
\text { response) }\end{array}$} \\
\hline & Yes & $59(33.9 \%)$ \\
\hline & No & $115(66.1 \%)$ \\
\hline \multirow[t]{7}{*}{5} & \multicolumn{2}{|c|}{ How many cardiac surgeries does your center perform per year? * (174 responses) } \\
\hline & $0-50$ & $5(2.9 \%)$ \\
\hline & $50-100$ & $6(3.4 \%)$ \\
\hline & $100-150$ & $14(8 \%)$ \\
\hline & $150-200$ & $7(4 \%)$ \\
\hline & $200-250$ & $14(8 \%)$ \\
\hline & $>250$ & $128(73.6 \%)$ \\
\hline \multirow[t]{7}{*}{6} & \multicolumn{2}{|c|}{ How many years have you been in practice as a cardiac surgeon? * (174 responses) } \\
\hline & $1-5$ years & $54(31 \%)$ \\
\hline & $5-10$ years & $36(20.7 \%)$ \\
\hline & $10-15$ years & $20(11.5 \%)$ \\
\hline & $15-20$ years & $22(12.6 \%)$ \\
\hline & $20-25$ years & $14(8 \%)$ \\
\hline & $>25$ years & $28(16.1 \%)$ \\
\hline \multirow[t]{3}{*}{7} & \multicolumn{2}{|c|}{$\begin{array}{l}\text { Did your center perform cardiac surgeries after March 24th } 2020 ? * \text { (after initiation of } \\
\text { nation-wide lock down)174 responses }\end{array}$} \\
\hline & Yes & $127(73 \%)$ \\
\hline & No & $47(27 \%)$ \\
\hline \multirow[t]{4}{*}{8} & \multicolumn{2}{|c|}{$\begin{array}{l}\text { If "Yes". what type of surgeries did you perform after March 24th 2020? (select all that is } \\
\text { applicable) (135 responses) }\end{array}$} \\
\hline & Emergency ( $<24$ hours) & $85(63 \%)$ \\
\hline & Urgent (with 2 days) & $108(80 \%)$ \\
\hline & Elective & $30(22.2 \%)$ \\
\hline \multirow[t]{3}{*}{9} & \multicolumn{2}{|c|}{$\begin{array}{l}\text { If you have performed elective cardiac surgery after March } 24 \text { th } 2020 \text {, how much reduction } \\
\text { of case volume is there compared to the non-covid time? ( } 118 \text { responses) }\end{array}$} \\
\hline & No reduction of case volume & $2(1.7 \%)$ \\
\hline & Less by $20 \%$ & 2 (1.7\%) \\
\hline
\end{tabular}




\begin{tabular}{|c|c|c|c|c|c|c|c|c|}
\hline & Less by $30 \%$ & \multicolumn{7}{|c|}{$3(2.5 \%)$} \\
\hline & Less by $40 \%$ & \multicolumn{7}{|c|}{6 (5.1\%) } \\
\hline & Less by more than $50 \%$ & \multicolumn{7}{|c|}{$105(89 \%)$} \\
\hline 10 & \multicolumn{8}{|c|}{$\begin{array}{l}\text { If you have performed Elective / Emergency / Urgent surgeries after March 24th, 2020, } \\
\text { please select the options below }\end{array}$} \\
\hline & & 守 & 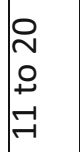 & $\begin{array}{l}\stackrel{0}{n} \\
\circ \\
+ \\
\stackrel{N}{N}\end{array}$ & 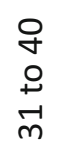 & 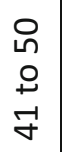 & $\begin{array}{l}8 \\
\circ \\
\stackrel{1}{1} \\
\text { ㄴ }\end{array}$ & $\stackrel{\circ}{\circ}$ \\
\hline & TVD with Chest pain at rest & 79 & 14 & 5 & 5 & - & - & 3 \\
\hline & Significant LMSD without chest pain & 72 & 7 & 4 & 4 & - & 1 & 3 \\
\hline & Stable TVD & 26 & 6 & 1 & 1 & 1 & - & - \\
\hline & $\begin{array}{r}\text { Mitral / Aortic valve pathology without Pulmonary } \\
\text { edema }\end{array}$ & 41 & 1 & 3 & 1 & - & - & - \\
\hline & Valve pathology with Pulmonary edema & 40 & 4 & 2 & - & - & - & 1 \\
\hline & Aortopulmonary shunt for CHD & 21 & 3 & 4 & - & - & - & - \\
\hline & Type A Acute aortic dissection & 24 & 1 & - & - & - & - & - \\
\hline & $\begin{array}{r}\text { Ascending aortic aneurysm }>5.5 \mathrm{~cm} \text { in non-BAV, non-CTS } \\
\text { cohort }\end{array}$ & 14 & 3 & - & - & - & - & - \\
\hline & Ascending aortic aneurysm $>4.5 \mathrm{~cm}$ in BAV / CTD cohort & 14 & - & 2 & - & - & - & - \\
\hline 11 & \multicolumn{8}{|c|}{$\begin{array}{l}\text { If you have stopped the elective surgeries after the nationwide lock down, when did you } \\
\text { stop? (135 responses) }\end{array}$} \\
\hline & Jan-20 & \multicolumn{7}{|c|}{$1(0.75 \%)$} \\
\hline & Feb-20 & \multicolumn{7}{|c|}{$1(0.75 \%)$} \\
\hline & Mar-20 & \multicolumn{7}{|c|}{$116(85.92 \%)$} \\
\hline & Apr-20 & \multicolumn{7}{|c|}{$10(7.40 \%)$} \\
\hline & May-20 & \multicolumn{7}{|c|}{$7(5.19 \%)$} \\
\hline 12 & \multicolumn{8}{|c|}{$\begin{array}{l}\text { If you have stopped elective surgeries due to COVID 19, have you resumed your routine } \\
\text { elective cardiac surgeries? (162 responses) }\end{array}$} \\
\hline & Yes & \multicolumn{7}{|c|}{$51(31.48 \%)$} \\
\hline & No & \multicolumn{7}{|c|}{$111(68.52 \%)$} \\
\hline 13 & \multicolumn{8}{|c|}{ If "Yes", when did you resume your elective surgery? (51 responses) } \\
\hline & Mar-20 & \multicolumn{7}{|c|}{$1(1.97 \%)$} \\
\hline & Apr-20 & \multicolumn{7}{|c|}{$14(27.45 \%)$} \\
\hline & May-20 & \multicolumn{7}{|c|}{$34(66.67 \%)$} \\
\hline & Jun-20 & \multicolumn{7}{|c|}{$2(3.92 \%)$} \\
\hline 14 & \multicolumn{8}{|c|}{ If "No", when do you expect to restart elective surgery? (111 responses) } \\
\hline & 3rd week of May 2020 & \multicolumn{7}{|c|}{$29(26.1 \%)$} \\
\hline & Last week of May 2020 & \multicolumn{7}{|c|}{$15(13.5 \%)$} \\
\hline & 1st week of June 2020 & \multicolumn{7}{|c|}{$34(30.6 \%)$} \\
\hline & 2nd week of June 2020 & \multicolumn{7}{|c|}{$12(10.8 \%)$} \\
\hline & 3rd week of June 2020 & \multicolumn{7}{|c|}{$1(0.9 \%)$} \\
\hline & 4th week of June 2020 & \multicolumn{7}{|c|}{$3(2.7 \%)$} \\
\hline
\end{tabular}




\begin{tabular}{|c|c|c|}
\hline & July or beyond & $17(15.3 \%)$ \\
\hline 15 & \multicolumn{2}{|c|}{$\begin{array}{l}\text { Has your "traditional" post-surgery ICU been transformed into a dedicated COVID-Unit ICU? } \\
\text { * } 174 \text { responses }\end{array}$} \\
\hline & Yes & $21(12.1 \%)$ \\
\hline & No & $153(87.9 \%)$ \\
\hline \multirow[t]{3}{*}{16} & \multicolumn{2}{|c|}{$\begin{array}{l}\text { Did your "traditional" post-surgery ICU move to another side of the hospital giving way for } \\
\text { COVID ICU? * (174 responses) }\end{array}$} \\
\hline & Yes & $17(9.8 \%)$ \\
\hline & No & $157(90.2 \%)$ \\
\hline \multirow[t]{2}{*}{17} & \multicolumn{2}{|c|}{ In the current climate how would you prioritize the following cases? } \\
\hline & Figure 3 & \\
\hline \multirow[t]{2}{*}{18} & \multicolumn{2}{|c|}{$\begin{array}{l}\text { In the present climate, what are the additional diagnostic test you would do for patients } \\
\text { requiring cardiac surgery in your unit? }\end{array}$} \\
\hline & Figure 4 & \\
\hline 19 & \multicolumn{2}{|c|}{$\begin{array}{l}\text { COVID-19 positive patients: Please list what protective measures should be followed during } \\
\text { and after a cardiac operation? }{ }^{*}(174 \text { responses) }\end{array}$} \\
\hline 20 & \multicolumn{2}{|c|}{$\begin{array}{l}\text { COVID-19 negative patients: Please list what protective measures should be followed during } \\
\text { and after a cardiac operation? * (174 responses) }\end{array}$} \\
\hline 21 & \multicolumn{2}{|c|}{ Did you use ECMO for any COVID positive patients in your hospital? * (174 responses) } \\
\hline & No & $100 \%$ \\
\hline 22 & \multicolumn{2}{|c|}{$\begin{array}{l}\text { If you have used ECMO, can you share your experience regarding the indications, } \\
\text { precautions and management specific to COVID19 positive patients }\end{array}$} \\
\hline 23 & \multicolumn{2}{|c|}{$\begin{array}{l}\text { Did you perform cardiac surgery on a COVID positive patient or on a patient who was } \\
\text { confirmed positive after the surgery? }{ }^{*}(174 \text { responses) }\end{array}$} \\
\hline 24 & No & $100 \%$ \\
\hline 25 & \multicolumn{2}{|c|}{$\begin{array}{l}\text { If "Yes", kindly share your experience in regards to presentation, surgical precaution and } \\
\text { postoperative management? }\end{array}$} \\
\hline 26 & \multicolumn{2}{|c|}{$\begin{array}{l}\text { When do expect cardiac surgery practice to go back to "Pre-COVID } 19 \text { pandemic period"? } \\
\text { *(174 responses) }\end{array}$} \\
\hline & 3 months & $2(1.1 \%)$ \\
\hline & 6 months & 82 (47.1\%) \\
\hline & 1 year & 71 (40.8\%) \\
\hline & 2 year & $15(8.6 \%)$ \\
\hline & 3 year & - \\
\hline & 4 year & - \\
\hline & 5 years or more & $1(0.6 \%)$ \\
\hline & Others & $3(1.72 \%)$ \\
\hline
\end{tabular}


Fig. 1 The response across each states has been represented. COVID hot states has been marked in blue

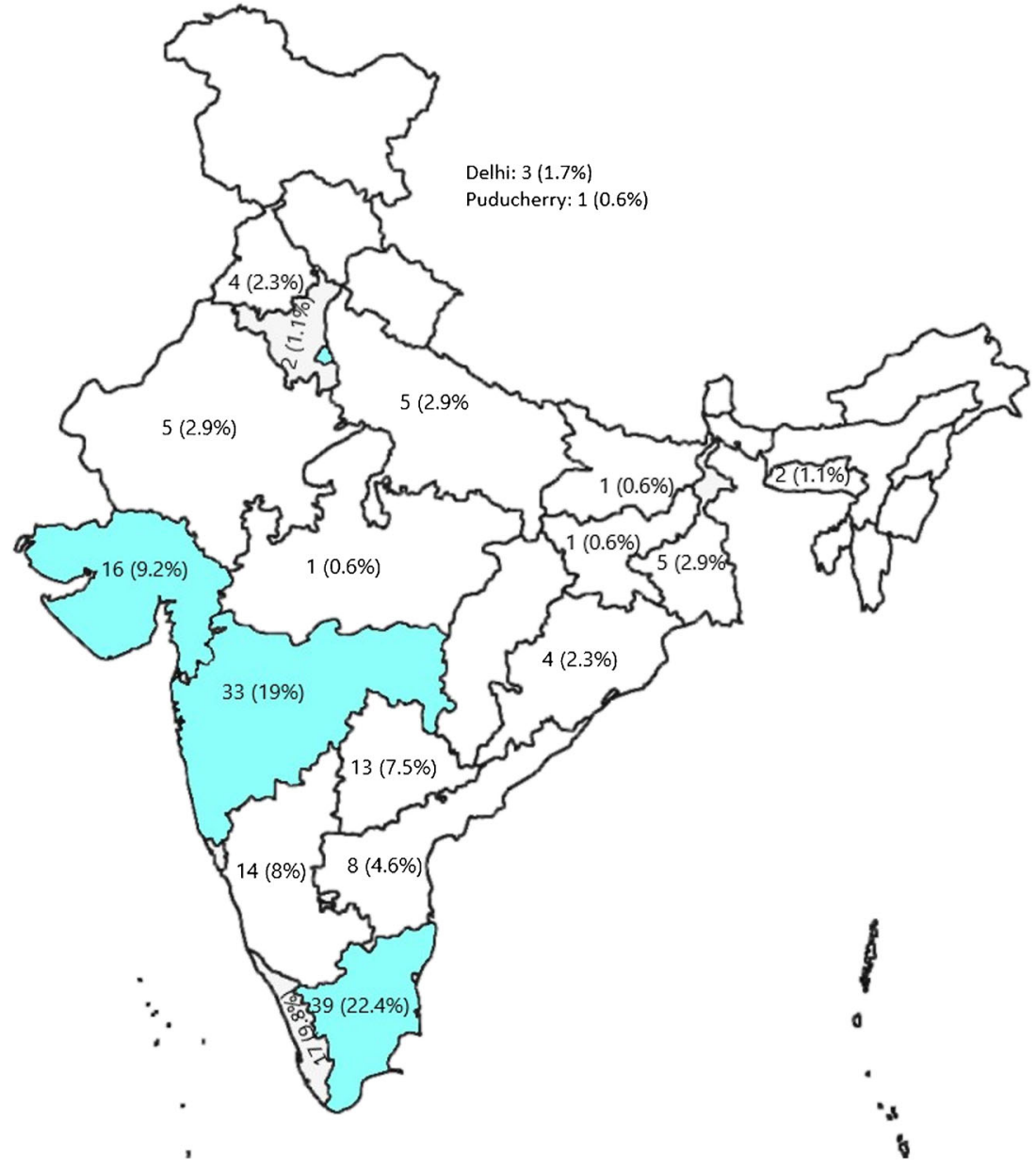

\begin{tabular}{|c|c|}
\hline Cities & $\begin{array}{l}\text { Number of } \\
\text { Responses / } \\
\text { city }\end{array}$ \\
\hline Chennai & 29 \\
\hline Mumbai & 26 \\
\hline Ahmedabad & 14 \\
\hline Bengaluru & 13 \\
\hline Hyderabad & 12 \\
\hline Kozhikode, Thiruvananthapuram, Kolkata & 5 \\
\hline Kochi, Bhubaneswar, Jaipur, Madurai & 4 \\
\hline Delhi, Mohali, Coimbatore & 3 \\
\hline $\begin{array}{l}\text { Guntur, Kurnool, Gurgaon, Aurangabad, Shillong, } \\
\text { Secunderabad, Kottayam }\end{array}$ & 2 \\
\hline $\begin{array}{l}\text { Vishakapatnam, Srikakulam, Patna, Surat, Vapi, } \\
\text { Ranchi, Hubli, Thiruvalla, Indore, Kolhapur, Nagpur, } \\
\text { Nasik, Pune, Shirdi, Puducherry, Jalandhar, Udaipur, } \\
\text { Perambalur, Thanjavur, Vellore, Karimnagar, Kanpur, } \\
\text { Noida, Aligarh, Lucknow, Agra }\end{array}$ & 1 \\
\hline
\end{tabular}

Fig. 2 The number of responses across the different cities

\section{Discussion}

Early reports attribute $40 \%$ of mortality in COVID-19 patients to cardiovascular causes. Further, patients with preexisting cardiovascular disease have a mortality of $11 \%$ [5]. There is death every 2 in 3 patients (69\%) if they sustain an acute myocardial injury [6]. At the end of the spectrum, we have patients with preexisting cardiac conditions, who may suffer lethal cardiac events if surgery is delayed by several weeks. India entered a phase of lockdown on March 24, 2020. There is a dramatic decrease in the surgical case volume and many centres postponed or delayed elective surgeries. There are several factors that delayed or postponed cardiac surgeryfear of mortality, fear of disease spread, shortage of blood donation rate and reduced number of angiograms performed. Further, there are reports suggesting patients are reluctant to go to hospital amidst the pandemic. This was coupled with the travel restriction and financial constrains during this economic crunch situation. Gradually there is easing out of the lockdown in a phased manner in different regions. We will be encountering patients who may be COVID positive or a COVID survivor. At present, there is no risk stratification 


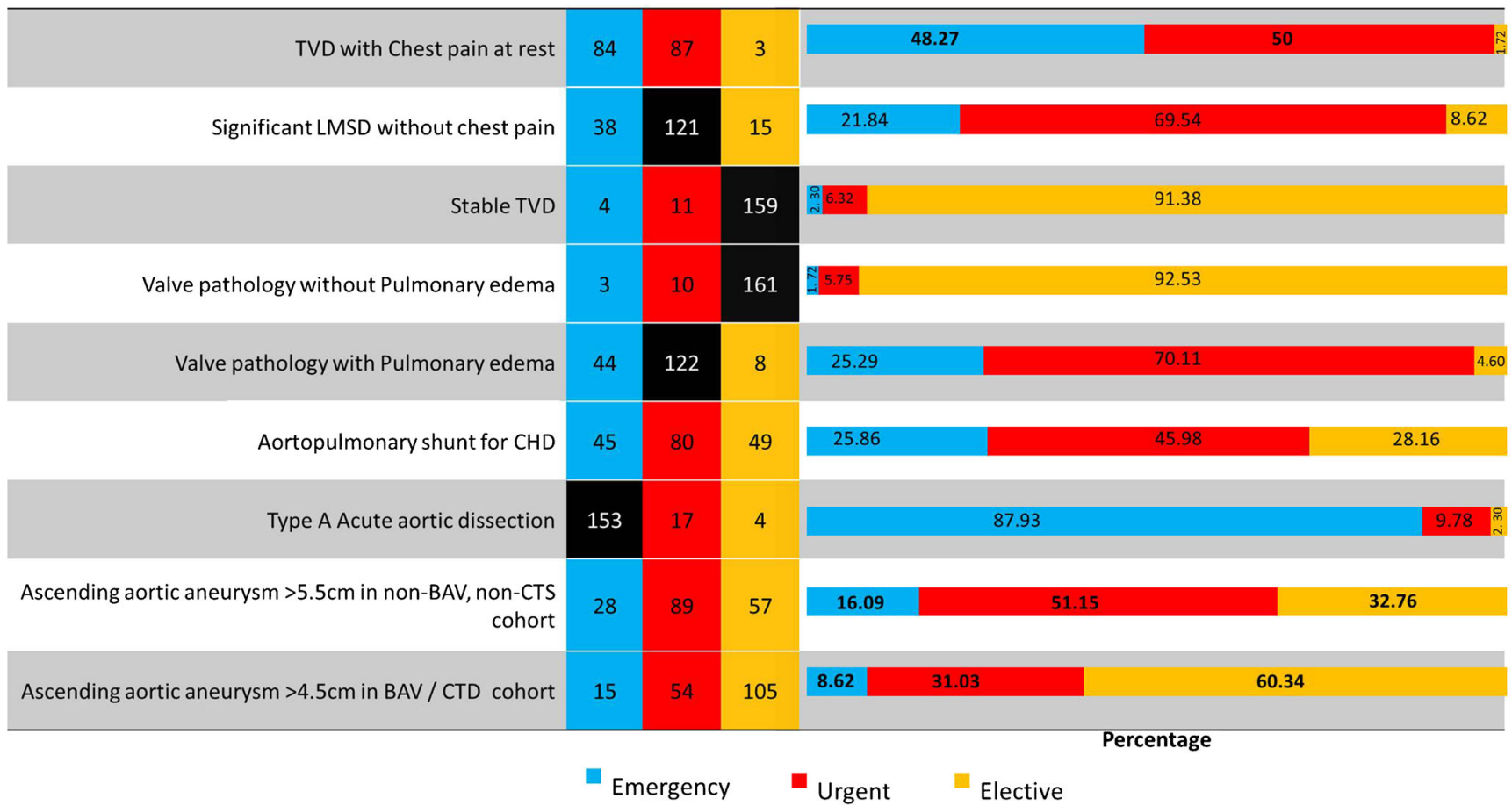

Fig. 3 Consensus among the surgeons on various cardiac surgery procedures. An effective consensus was considered when $>70 \%$ of surgeons agreed on the same option (marked in black boxes), while moderate consensus was considered when $>50 \%$ of surgeons agreed on the same option

model which includes COVID-19, predicting the outcome of the procedure. This makes patients' counselling and consents difficult. Clinical outcomes are slowly agglomerating across the world, as centres start to encounter these subsets of patients. It may take another couple of months before we can receive evidence on these patients. The American College of Surgeons has provided guidance in triaging elective patients in various other specialties, excluding cardiac surgery [7]. There are three main critical issues of cardiovascular surgery in this pandemic:

1. Preoperative investigations

2. Prioritizing the surgical procedures

3. Personal protection equipment

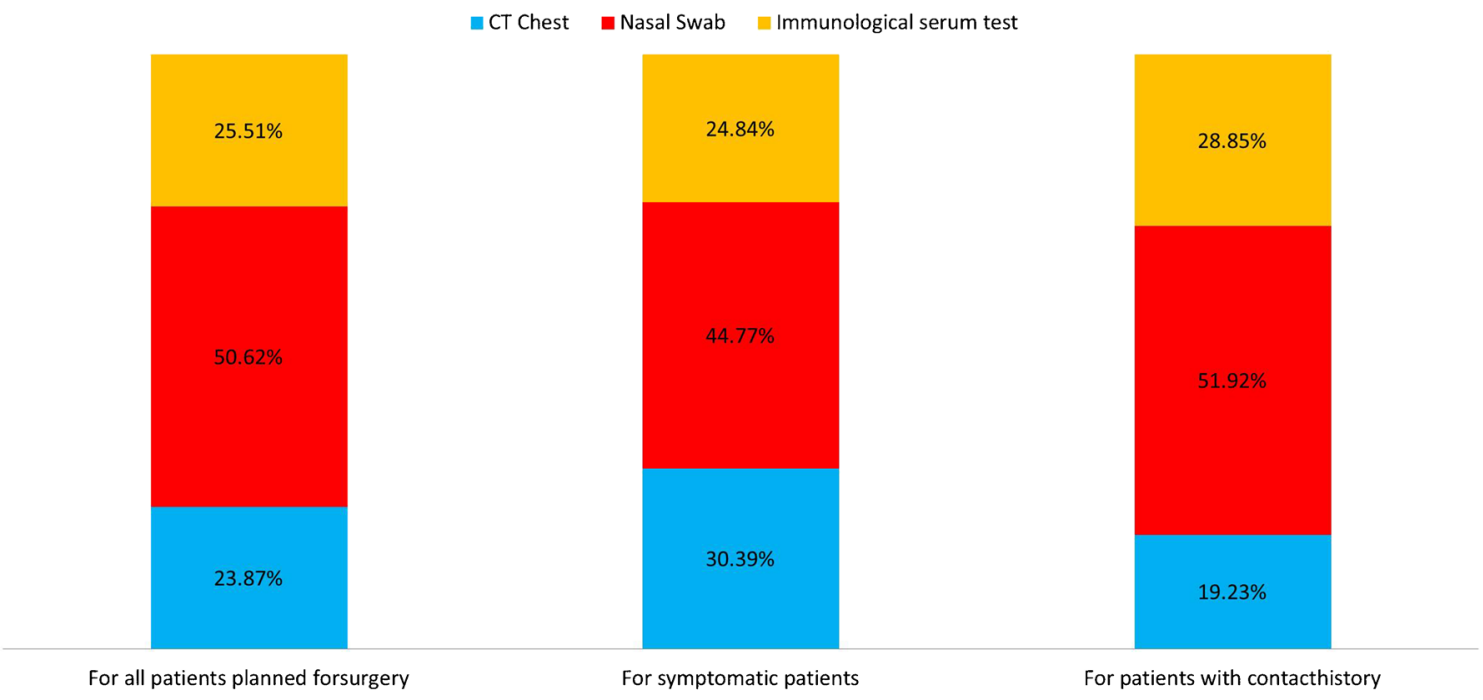

Fig. 4 Consensus among the surgeons on the choice of investigation for patients 


\section{Preoperative investigations}

Testing strategies for GOI are framed by Indian Council for Medical Research (ICMR) keeping in mind the optimal usage of available resources. The ICMR does not recommend testing for COVID-19 for all hospital admissions, except pregnant women residing in containment areas or infection clusters [8].

The rationale for surgeons to do COVID-19 tests prior to surgery includes as follows: (i) SARS-CoV-2 is a highly infectious disease and has a high transmission that happens in the presymptomatic period (i.e. individuals who have COVID-19 but do not yet show any symptoms of the disease). (ii) It is very difficult to diagnose COVID-19 based on history alone and (iii) difficult to distinguish COVID-19 pneumonia from other viral pneumonia on computed tomography (CT) findings alone. (iv) Cardiac surgery patients are particularly vulnerable to pulmonary complication. Exposure of these patients to COVID-19 prior to surgery may have a deleterious effect on outcomes. (v) Cardiovascular surgery is teamwork, where team members work in close proximity. A single positive member in the team is likely to infect many health care workers and impact the hospital functioning. (vi) This can increase the overall testing figures of the country and will help in identifying asymptomatic carriers. These are not without limitations which include (i) cost of the test and availability of the test and (ii) time delay for the final report (12 to $24 \mathrm{~h}$ ). (iii) The sensitivity of reverse transcription polymerase chain reaction (RT PCR) alone is only 66\% (giving a false sense of security).

Though practically not possible, ideally 14 days of quarantine is essential for the optimal detection of COVID-19 patients with symptoms [9]. Though chest CT lacks specificity, it has a high sensitivity index for COVID-19 when compared with RT PCR. Hence, chest CT has been used by a number of centres and may have a role in certain situations [10,11].

Anticipating the limited resources, it has been proposed to follow a pretest probability stratified approach for testing. The pretest probability is based on the presence of symptoms, travel and exposure history, and the community prevalence of the disease. The rationale for the pretest probability stratified approach is that, in low-prevalence settings, the positive predictive value is low; and in high-prevalence settings, the negative predictive value is low [12].

There is every probability that an asymptomatic patient with negative RT PCR can become positive during the hospital stay. Hence, a few centres advise 'Exit RT-PCR testing' or 7-day post-operative day testing, whichever is later to check the COVID status of the patient [13].

\section{Prioritizing the surgical procedures}

We will be encountering patients who are COVID-19 positive, COVID survivors, COVID-19 exposed and COVID-19 negative. The consensus for the optimal perioperative approach for COVID-19 patients who require cardiac surgery is lacking. The angiotensin-converting enzyme II, which is protective against lung injury, may have been consumed by SARS-CoV-2 entry, making these patients more susceptible to post-operative complications [14-17]. It is unclear how contagious patients who have recovered from COVID-19 are, and hence, it has been recommended to delay cardiac surgery for a minimum of 2 to 4 weeks in patients who have recently recovered from COVID-19 [12].

During this unprecedented time, we are faced with some critical, yet unanswered questions. Clinically and ethically, which are the patients we can delay? Which pathology can wait? Is it ethical to treat a young, uncomplicated patient rather than an elderly or a complicated patient to shorten the ICU stay and maximize the resources' utility?

Waiting period There were several reports earlier for risk stratification and, to establish a 'maximum waiting period,' for cardiac surgery. This would be useful in the present climate to redeploy the resources to COVID-19 patients. A simple scoring system for CABG was retrospectively validated for 5167 patients [18]. The overall mortality rate was $0.8 \%$ during the waiting period in these patients. The severity ranges between high score (six points or higher), intermediate score (35 points), and a low score ( $0-2$ points), and they indicate the need for surgery within 2 weeks, 12 weeks, and 6 months, respectively.

Coronary artery There is a general consensus that stable TVD can be planned for elective surgery. The majority of the surgeons have consented that asymptomatic significant LMSD can be planned for urgent surgery. In a survey from the UK, a third of responders suggested percutaneous cardiac interventions (PCI) be considered a default strategy and surgery to be considered only in unstable patients [19]. Following cardiac surgery, patients are more prone to respiratory compilations compared with PCI which increases the morbidity and mortality in the present era. Hence, PCI can be offered as a temporary solution to these patients. In patients with COVID-19, unless requiring emergency surgery, we advocate a delay in surgery until recovered or a PCI, if surgery cannot be delayed. COVID-19 patients appear to be at a higher risk for thrombotic disease states including acute coronary syndrome and venous thromboembolism. Hence, these patients undergoing coronary stenting may be at an increased risk and the ideal antiplatelet therapy in these patients needs further investigation [20]. Matt and Maisano stated in PCRonline "patients with acute coronary syndrome in case of severe coronary artery disease (e.g. severe left main trunk stenosis, severe triple vessel disease with high SYNTAX score) who are not eligible for conservative or interventional treatment may be operated on.' [21]. 
Aortic and mitral valves The majority of the surgeons believe that surgery on the aortic/mitral valve in the present era should be considered in selected cases only [7]. Surgery is suggested in symptomatic severe aortic valve stenosis, left-sided endocarditis with a severe valve defect, symptomatic severe mitral valve insufficiency and/or signs of cardiac function impairment $[12,21,22]$. Mitral/aortic valve pathology with chronic heart failure can be deferred for 4 to 12 weeks [12]. In authors' opinion, patients with valve pathology with pulmonary oedema need adequate medical stabilization before being considered for surgery. These patients are vulnerable to respiratory complications adding to the morbidity in the present era. Asymptomatic valve pathology without pulmonary oedema can be advised for medical management and, if they require surgery, can be safely deferred [12].

Vascular surgery The American College of Surgery [7] has categorized patients into three categories-Do not postpone, Postpone if possible and Postpone. Ruptured or symptomatic aneurysms, aneurysm with signs of impending rupture or malperfusion and aneurysm associated with infections are placed in the category of 'Do not postpone'. Acute aortic dissection, acute limb ischaemia and symptomatic carotid artery stenosis are to be operated without any postponement. Asymptomatic aneurysms, even abdominal aortic aneurysm $($ AAA $)$ /thoracoabdominal aortic aneurysm $($ TAAA) $>$ $6.5 \mathrm{~cm}$, can consider postponement in the present situations.

\section{Self-protection}

Figures from China show that more than 3300 health care workers (HCW) were infected as of early March 2020. In Italy, one-fifth of the responding HCW were infected with some losing their lives [23]. Though the official report is not available, a report says at least 90,000 $\mathrm{HCW}$ worldwide and 548 doctors, nurses and paramedics across India are believed to have been infected with COVID-19 so far as on May 6, 2020 [24]. The following recommendations are based on the consensus of the survey and available literature $[12,25,26]$. They are tailored to the needs of the clinical practice in India.

Surgeons are exposed to the COVID-19 at three different stations - outpatient services, OR and post-operative ICU, inpatient ward.

Outpatient services This is the most vulnerable area where surgeons can be exposed to SARS-CoV-2. All patients and their accompanying person need to be screened and triaged accordingly. If the patient can manage on their own, it is advisable only the patient is allowed inside the hospital. To reduce crowding in the outpatient service, we need to adhere to the following: (i) arrival of patient at their slot time; (ii) ensuring availability of all patient record in an orderly manner; (iii) 'social distancing' should be followed as much as possible during interaction.

Operating room The highest risk is encountered during aerosol-generating procedures (AGP) which include intubation, extubation, tracheostomy, bronchoscopy, any cardiac or thoracic surgery, chest tube placement and Bovie cautery use. The use of an N95 respirator or powered air-purifying respirator, eye protection, gloves and gowns is recommended for these procedures in COVID-19-suspected or COVID-19positive patients [27-29]. Anaesthetists intubate and prepare the patient with minimal personnel inside. The optimal duration to wait before allowing non-anaesthesia staff into the OR is unknown. The authors recommend a time-lapse of a minimum half an hour between completion of anaesthetic preparation and surgical incision allowing the droplets to settle down. The assisting nurse drapes the patient and the surgeon scrubs after the draping are complete. The PPE suit recommended for the surgical team is shown in Fig. 5. Every effort is made for social distancing in the OR, though difficult.

Shifting of a patient from the OR to ICU is a very crucial step and the workforce in a particular OR should be engaged. This will avoid any cross-contamination between two different theatres. The nurses should adhere to the unit protocols and should not breach during changing of work shift. The PPE for respiratory therapists and physiotherapists is shown in Fig. $5 \mathrm{c}$. Clinical examination by the physicians should be limited with a strict practice of hand hygiene. Visitation of relatives is limited to very sick patients and one post-operative visit.

Inpatient ward One relative from admission to discharge should be insisted upon. Any person staying with the patient should not be leaving the hospital premises during this period. The surgical team should wear mask, face shield and gloves during the daily rounds. Social distancing should be practised as much as possible with patient handling only when required. Early discharge should be aimed for.

\section{Limitations of the study}

The aim of the present survey was to understand the impact of clinical decision-making during this pandemic era among the cardiothoracic surgeon practising in India. Considering the fluidity of the situation and evolving evidence, these are only the consensus of the surgeons who participated in the survey. Our results may be biased if the practice preferences of the remaining cohort who did not participate vary significantly. This consensus can change as more evidence emerges in the future. Few of the recommendations may be difficult to implement in a specific region and hospital system. The investigators had no way of validating that the responses from the respondents did indeed correspond to the actual practice 
Fig. 5 Cartoon representation of personal protection equipment. a Surgical/anaesthesia team. b Circulation staff nurse in the operation theatre. $\mathbf{c}$ Intensive care unit staff/physiotherapist/respiratory technician
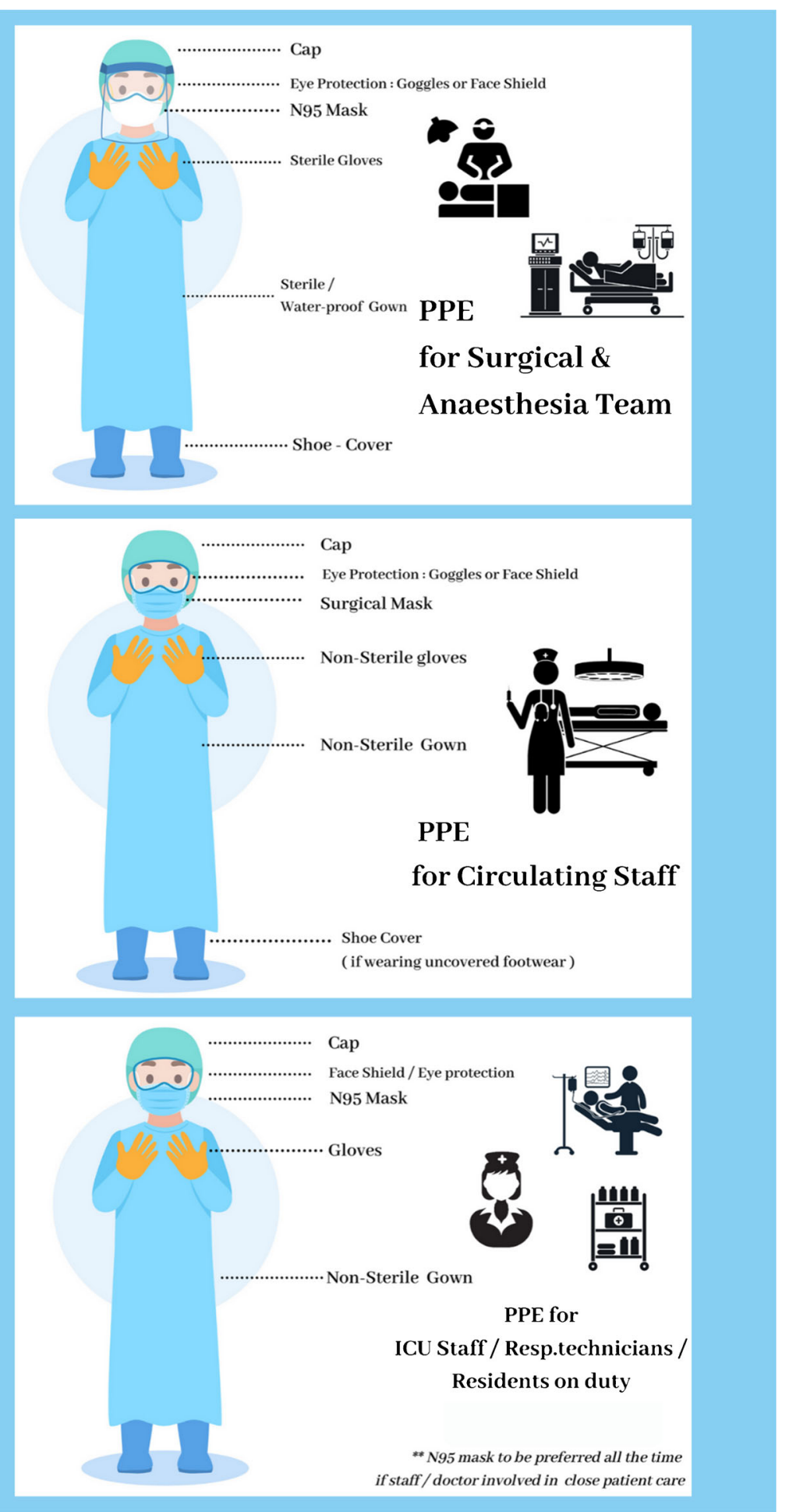

patterns. The authors accept that there were no precise measures to validate the questionnaire. Due to the dual contact method, some non-member cardiac surgeon of the IACTS may have responded to the survey. However, this number would be extremely small and it is anticipated that it would not make much difference to the calculation of the response rate.

\section{Conclusion}

The present situation is very fluid, changing on the daily basis. On one side, we need to deploy HCW for treating and containing the spread of infection; on the other hand, we also have to brace our health care system for any potential major outbreak. Pathogenesis of the disease is still not well established 
making the clinical decision difficult. With lack of guideline for guidance, consensus and expert opinion is the road ahead in this challenging time. This will allow the physicians to overcome the challenges in the interim.

Acknowledgements We wish to thank all the members of the IACTS for their time and effort to fill out the survey form. We thank Dr. Suthanthira Kannan, Department of Community Medicine, ESIC Medical College, Hyderabad, for his support in statistical analysis.

\section{Funding $\mathrm{Ni}$}

\section{Compliance with ethical standards}

Conflict of interest The authors declare that they have no conflict of interest.

Consent of participation and publication The following statement was mentioned during the survey. 'The response shall be pooled for analysis and academic presentations. On completion of the analysis, it will be submitted to the Indian Journal of Thoracic and Cardiovascular Surgery for consideration for publication. By taking this survey, you agree that the pooled data could be used by the survey team for academic/research purposes'.

Ethical statement This is an electronic survey which involves the cardiovascular and thoracic surgeons of India. There is no human or animal experiment involved. The identity of the surgeons was anonymized in the survey. An expedited clearance was obtained from the Institutional Review Board.

Human and animal rights statements There is no human or animal involved in any experiment in the present study.

\section{References}

1. Thayyil J, Cherumanal JM. Issues of creating a new cadre of doctors for rural India. Int J Med Public Health. 2013;3(1):8-11.

2. Updated July 12th, 2020, https://www.worldometers.info/ coronavirus/\#countries, Accessed July 12th, 2020

3. Updated July 12th, 2020, https://ourworldindata.org/coronavirus. Accessed July 12th, 2020.

4. Haft JW, Atluri P, Alawadi G, et al. Adult cardiac surgery during the COVID-19 Pandemic: A tiered patient triage guidance statement. Ann Thorac Surg. 2020.https://doi.org/10.1016/j.athoracsur. 2020.04.003.

5. Ruan Q, Yang K, Wang W, Jiang L, Song J. Correction to: Clinical predictors of mortality due to COVID-19 based on an analysis of data of 150 patients from Wuhan, China. Intensive Care Med. 2020;46:1294-1297. https://doi.org/10.1007/s00134-020-06028-z.

6. Guo T, Fan Y, Chen M, et al. Cardiovascular implications of fatal outcomes of patients with coronavirus disease 2019 (COVID-19). JAMA Cardiol. 2020. https://doi.org/10.1001/jamacardio.2020. 1017.

7. Online March $24^{\text {th }}, 2020$. COVID19: elective case triage guidelines for surgical care 2020. https://www.facs.org/covid-19/clinicalguidance/elective-case.Accessed on June30th, 2020

8. https://www.icmr.gov.in/pdf/covid/strategy/Testing_Strategy_v5 18052020.pdf. Accessed on June30th, 2020

9. Lauer SA, Grantz KH, Bi Q, et al. The incubation period of Coronavirus Disease 2019 (COVID-19) from publicly reported confirmed cases: estimation and application. Ann Intern Med. 2020;172:577-582. https://doi.org/10.7326/M20-0504.

10. Ai T, Yang Z, Hou H, et al. Correlation of chest CT and RT-PCR testing in Coronavirus Disease 2019 (COVID-19) in China: a report of 1014 cases. Radiology. 2020;200642. https://doi.org/10.1148/ radiol.2020200642.

11. Majidi H, Niksolat F. Chest CT in patients suspected of COVID-19 infection: A reliable alternative for RT-PCR. Am J Emerg Med. 2020;S0735-6757(20):30244-8.

12. Patel V, Jimenez E, Cornwell L, et al. Cardiac surgery during the Coronavirus Disease 2019 Pandemic: perioperative considerations and triage recommendations. J Am Heart Assoc. 2020;9:e17042.

13. Al-Muharraqi MA. Testing recommendation for COVID-19 (SARS-CoV-2) in patients planned for surgery - continuing the service and 'suppressing' the pandemic. Br J Oral Maxillofac Surg. 2020;58:503-505.

14. Imai $\mathrm{Y}, \mathrm{Kuba} \mathrm{K}, \mathrm{Rao} \mathrm{S}$, et al. Angiotensin-converting enzyme 2 protects from severe acute lung failure. Nature. 2005;436:112-116.

15. Hoffmann M, Kleine-Weber H, Schroeder S, et al. SARS-CoV-2 Cell entry depends on ACE2 and TMPRSS2 and is blocked by a clinically proven protease inhibitor. Cell. 2020;181:271-280.e8.

16. Shang J, Ye G, Shi K, et al. Structural basis of receptor recognition by SARS-CoV-2. Nature. 2020;581:221-224. https://doi.org/10. 1038/s41586-020-2179-y.

17. Yan R, Zhang Y, Li Y, Xia L, Guo Y, Zhou Q. Structural basis for the recognition of SARS-CoV-2 by full-length human ACE2. Science. 2020;367:1444-1448. https://doi.org/10.1126/science. abb2762.

18. Rexius H, Brandrup-Wognsen G, Nilsson J, Odén A, Jeppsson A. A simple score to assess mortality risk in patients waiting for coronary artery bypass grafting. Ann Thorac Surg. 2006;81:577-582. https://doi.org/10.1016/j.athoracsur.2005.08.032.

19. Benedetto U, Goodwin A, Kendall S, Uppal R, Akowuah E. A nationwide survey of UK cardiac surgeons' view on clinical decision making during the COVID-19 pandemic. J Thorac Cardiovasc Surg. 2020;S0022-5223(20)31167-3. https://doi.org/10.1016/j. jtcvs.2020.05.016.

20. Awad WI, Idhrees M, Kennon S, Bashir M. Coronary artery bypass grafting surgery versus percutaneous coronary intervention: what is the clinical decision framework amid COVID-19 era? [published online ahead of print, 2020 Jul 11]. J Card Surg. 2020. https://doi. org/10.1111/jocs.14833.

21. https://www.pcronline.com/News/Whats-new-on-PCRonline/ 2020/Cardiac-Surgery-and-the-COVID-19-outbreak-what-does-itmean. Accessed June $1^{\text {st }}, 2020$

22. Del Giglio M , Tamagnini G. Cardiac surgery in the time of coronavirus. Braz J Cardiovasc Surg. 2020;35:X-XI. https://doi.org/10. 21470/1678-9741-2020-0161.

23. COVID-19: protecting health-care workers. Lancet. 2020;395: 10228. https://doi.org/10.1016/S0140-6736(20)30644-9.

24. May 6th, 2020. https://www.hindustantimes.com/india-news/548docs-nurses-paramedics-infected-with-covid-19-across-indiareport/story-o2pM3w2adM4g3PXI6TBlkN.html. Accessed on June $1^{\text {st }}, 2020$.

25. Personal protective equipment for COVID-19. World health organization. Updated April 6th, 2020 https:/www.who.int/medical devices/priority/COVID 19 PPE/en/. Accessed June 30, 2020.

26. Ortega R, Gonzalez M, Nozari A, Canelli R. Personal Protective Equipment and Covid-19. N Engl J Med. 2020;382:e105. https:// doi.org/10.1056/NEJMvem2014809.

27. Zucco L, Levy N, Ketchandji D, Aziz M, Ramachandran SK. Perioperative considerations for the 2019 novel coronavirus (COVID-19). Anesthesia Patient Safety Foundation Updated March 10, 2020. https://www.apsf.org/news-updates/ perioperative-considerations-for-the-2019-novel-coronaviruscovid-19/. Accessed June 30, 2020. 
28. Coronavirus disease 2019 (COVID-19) interim infection prevention and control recommendations. Centers for Disease Control and Prevention. Updated June 19, 2020. https://www.cdc.gov/ coronavirus/2019-ncov/infection-control/controlrecommendations.html?CDC_AA_refVal=https $\% 3 \mathrm{~A} \% 2 \mathrm{~F} \%$ 2Fwww.cdc.gov $\% 2 \mathrm{~F}$ coronavirus $\% 2$ F2 2019-ncov\%2Fhcp $\%$ 2Finfection-control.html. Accessed June 30, 2020.
29. COVID-19: considerations for optimum surgeon protection before, during and after operation. American College of Surgeons. Updated April 1, 2020. https://www.facs.org/covid-19/clinical-guidance/ surgeon-protection. Accessed June 30, 2020.

Publisher's note Springer Nature remains neutral with regard to jurisdictional claims in published maps and institutional affiliations. 